\title{
Ellis Van Creveld Syndrome - A perinatal autopsy case report
}

\author{
Rajashree Pradhan ${ }^{1}$, Sajeeb Mondal ${ }^{2}$, Shouvanik Adhya ${ }^{3}$ \\ ${ }^{I}$ (Department of Pathology, North Bengal Medical College, Siliguri, West Bengal, India) \\ ${ }^{2}$ (Department of Pathology, Sagar Dutta Medical College, Kolkata, West Bengal, India) \\ ${ }^{3}$ (Department of Forensic Medicine, College of Medicine \& JNM Hospital, Kalyani, West Bengal, India)
}

\begin{abstract}
Ellis Van Creveld syndrome is a disease complex where all the three embryonic layers appear to be involved. This disorder is also called chondro ectodermal dysplasia or meso ectodermal dysplasia. It is a part of an emerging class of diseases called ciliopathies due to primary dysfunction of cilia. It is very rare; only about 150 cases have been described in the world literature and rarely been described in the Indian literature. In our case perinatal autopsy was performed of a still born baby of 32 wks gestation having syndactyly and polydactyly and short forearm, to know the cause of death, and the diagnosis was emerged as Ellis Van Creveld syndrome. In India most of the intrauterine death cases remain undiagnosed, but diagnosis of EVC syndrome is important because it is transmitted as autosomal recessive manner so genetic counseling is required to make the parents aware of the risk of recurrence.
\end{abstract}

Keywords - Ellis Van Creveld syndrome, perinatal autopsy, polydactyly

\section{INTRODUCTION}

Ellis Van Creveld syndrome is a rare genetic disorder of skeletal dysplasia type. The cardinal features usually present as tetrad of : a) disproportionate small stature with increasing severity from the proximal to distal portions of the limbs. b) Polydactyly, affecting hands and occasionally the feet. c) Hydrotic ectodermal dysplasia mainly affecting the nails, hair and teeth. d) Congenital heart malformations occurring in about 50\%$60 \%$ of cases and comprising of single atrium, defects of the mitral and tricuspid valves, patent ductus, ventricular septal defect, atrial septal defect and hypoplastic left heart syndrome. The presence of congenital heart disease may support the diagnosis of the EVC syndrome and appears to be the main determinant of longevity. ${ }^{[1]}$ It is transmitted as autosomal recessive trait and caused by mutation of EVC gene ( both EVC1 and EVC2 ) and the locus is 4p16. ${ }^{[2]}$ The largest pedigree of EVC syndrome has been described in the old order Amish community in Lancaster County, Pennsylvania. ${ }^{[3]}$ The disorder was described first by Richard W. B. Ellis (1902-1966) of Edinburgh and Simon van Creveld (1895- 1971) of Amsterdam. ${ }^{[4]}$ Respiratory insufficiency due to thoracic dysplasia and cardiac anomalies are responsible for the majority of deaths in infancy. Herein we are presenting this case as it is a rare genetic disorder. Though the exact prevalence of this illness is unknown, around 150 cases have been described in the literature. ${ }^{[5]}$ Perinatal death due to EVC syndrome has been rarely reported in the Indian literature.

\section{CASE REPORT}

In this case a 36 year old mother delivered a still born baby at $32^{\text {nd }}$ week of gestation. Autopsy was performed following standard protocol. On external examination the baby had very short forearms "Fig.1", syndactyly and polydactyly in the left foot "Fig.2", finger nail dysplasia, flat pinna, imperforate anus "Fig.3". $\mathrm{X}$-ray of the dead baby showed absent radius in the left forearm "Fig.4". Dissection and internal examination showed atrial septal defect (ASD) and absence of kidney in one side. Histo pathological study after formalin fixation using $\mathrm{H} / \mathrm{E}$ stain from different tissues failed to detect any obvious abnormality except chondrocytic degeneration. After reviewing the literature and considering all the clinical features and the skeletal survey of the still born baby the final autopsy diagnosis was made as Ellis Van Creveld Syndrome. Genetic study was not done due to lack of facility.

\section{DISCUSSION}

Ellis Van Creveld Syndrome is quite rare. The birth prevalence of the syndrome has been estimated to be 7 per 1,000,000 population. ${ }^{[6]}$

Chondrodystrophy is the most common clinical feature, affecting the tubular bones producing a serious ossification defect. ${ }^{[1]}$ In consequence, the distal part of the limbs are small, leading to short stature. ${ }^{[5]}$ Congenital heart malformations are described in 50 to $60 \%$ of patients affected by this syndrome. Defects of the mitral and tricuspid valves, patent ductus arteriosus, ventricular septal defects and atrial septal defects are some of the malformations described as the principal cause of decreased life-expectancy in these patients. ${ }^{[1]}$ Additional clinical findings affecting other organs (lungs, kidneys, liver, pancreas and central nervous system) 
may occasionally be observed. Genitourinary anomalies such as agenesis and renal dysplasia, ureter ectasia and nephrocalcinosis usually present in $20 \%$ of cases ${ }^{[6]}$

In our case the baby had syn and polydactyly, absent radius in forearm, finger nail dysplasia and atrial septal defect fulfilling all the features of clinical tetrad. Association of paternal consanguinity has been found to be in $30 \%$ of cases. ${ }^{[6]}$

Ellis Van Creveld Syndrome can be diagnosed during the prenatal period starting from the 18th week of gestation, by ultrasonography. ${ }^{[7]}$ Molecular genetic testing (DNA mutation analysis) can be done by amniocentesis or chorionic villi biopsy. ${ }^{[8]}$

Differential diagnosis includes Jeune syndrome and Orofaciodigital syndromes. ${ }^{[9]}$ Jeune syndrome is a rare, potentially lethal, autosomal recessive disease; characterized by thoracic dystrophy, short limbs, small stature, polydactyly and generalized bony dysplasia. There are anomalies in pigmentation of the retina, renal involvement and hypoplastic lungs. ${ }^{[10]}$ The orofaciodigital syndromes result from dominant sex-linked inheritance, are limited to women. This is clinically characterized by multiple gingivolabial frenula, hypoplasia of the nasal cartilages, moderate mental retardation \& fissured tongue. Ankyloglossia is found in one third of such cases. ${ }^{[11]}$

$50 \%$ of patients of Ellis Van Creveld Syndrome die in infancy due to thoracic dysplasia leading to respiratory insufficiency and cardiac anomalies. Patients who survive infancy have a normal life expectancy. ${ }^{[12]}$

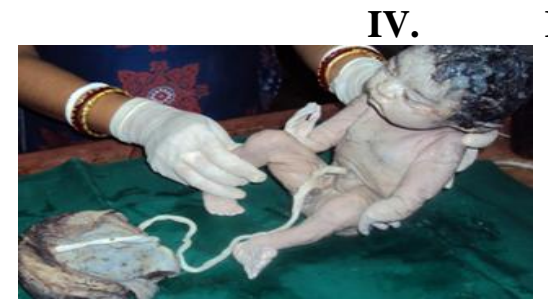

Fig. 1: short forearm

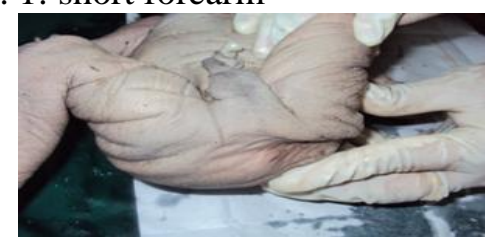

Fig. 3 : imperforate anus
FIGURES

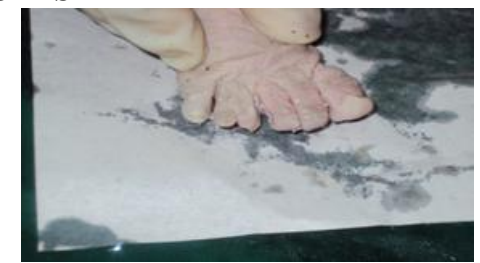

Fig. 2 : syndactyly \& polydactyly

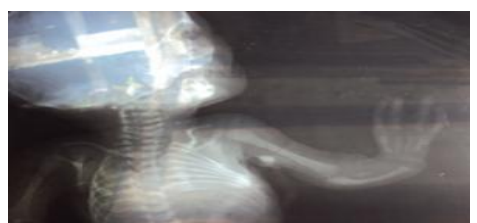

Fig. 4 : absent radius

\section{CONCLUSION}

Though this syndrome is a rare entity, but pre natal diagnosis is possible by use of ultrasonography. Genetic screening is not required to detect but genetic counseling is required to make the parents aware of the risk of recurrence. There should be social awareness regarding association of different types of genetic disorders with consanguineous marriage .Treatment is mainly symptomatic for cardio-respiratory problems along with supportive dental care. Surgical intervention may be required to correct orthopaedic malformations and cardiac defects.

\section{REFERENCES}

[1] Blackbum M , Belliveau R: Ellis-van Creveld syndrome: a report of previously undescribed anomalies in two siblings. Am J Dis Child 1971, 122:267-270

[2] Gorlin RJ, Cohen MM Jr, Levin LS. Syndromes of the head and neck. 3rd ed. New York: Oxford Univ Press, 1990

[3] McKusick VA. Ellis-van Creveld syndrome and the Amish. Nat Genet Mar 2000;24:203-204

[4] "Ellis-van Creveld syndrome" . Genes and Diseases. NCBI. 1998. Retrieved November 8, 2010

[5] Arya L, Mendiratta V, Sharma RC, Solanki RS. Ellis-van Creveld Syndrome: a report of two cases. Pediatr Dermatol. 2001;18:485-9

[6] Atasu M, Biren S. Ellis-van Creveld syndrome: Dental, clinical, genetic and dermatoglyphic findings of a case. J Clin Paediatr Dent 2000;24:141-5.

[7] Digoy GP, Greenberg M, Magit A. Congenital stridor secondary to an upper airway cyst in a patient with Ellis-van Creveld syndrome.Int J Pediatr Otorhinolaryngol. 2005;69:1433-5

[8] Baujat G, Le Merrer M. Ellis-van Creveld syndrome. Orphanet J Rare Dis. 2007;2:27.

[9] Ruiz-Perez VL, Ide SE, Strom TM, Lorenz B, Wilson D, Woods K, et al. Mutations in a new gene in Ellis-van Creveld syndrome and Weyers acrodental dysostosis. Nat Genet2000;24:283-286. Erratum: Nat Genet 2000;25:125

[10] Tompson SW, Ruiz-Perez VL, Blair HJ, Barton S, Navarro V,Robson JL, et al. Sequencing EVC and EVC2 identifies mutations in two-thirds of Ellis-van Creveld syndrome patients. Hum Genet.2007;120:663-70.

[11] Ghosh S, Setty S, Sivakumar A, Pai KM. Report of a new syndrome :focus on differential diagnosis and review of Ellis-Van Creveld, Curry-Hall, acrofacial dysostosis, and orofacial digitalsyndromes. Oral Surg Oral Med Oral Pathol Oral Radiol Endod.2007;103:670-6

[12] Harper JI, Trembath RC. Genetics and genodermatoses. In: Burns T,Breathnach S, Cox N, Griffiths C,editors. Rook's Textbook ofDermatology, 7 th edn. London:Blackwell Science; 2004. p. 12-48 